\title{
p-type behavior in nominally undoped ZnO thin films by oxygen plasma growth
}

\author{
Y. J. Zeng, Z. Z. Ye, ${ }^{\text {a) }}$ W. Z. Xu, J. G. Lu, H. P. He, L. P. Zhu, and B. H. Zhao \\ State Key Laboratory of Silicon Materials, Zhejiang University, Hangzhou 310027, \\ People's Republic of China \\ Y. Che \\ IMRA America, Inc., 1044 Woodridge Avenue, Ann Arbor, Michigan 48105
}

S. B. Zhang

National Renewable Energy Laboratory, Golden, Colorado 80401

(Received 21 March 2006; accepted 13 May 2006; published online 28 June 2006)

\begin{abstract}
We report on intrinsic $p$-type $\mathrm{ZnO}$ thin films by plasma-assisted metal-organic chemical vapor deposition. The optimal results give a resistivity of $12.7 \Omega \mathrm{cm}$, a Hall mobility of $2.6 \mathrm{~cm}^{2} / \mathrm{V} \mathrm{s}$, and a hole concentration of $1.88 \times 10^{17} \mathrm{~cm}^{-3}$. The oxygen concentration is increased in the intrinsic $p$-type $\mathrm{ZnO}$, compared with the $n$-type layer. Two acceptor states, with the energy levels located at 160 and $270 \mathrm{meV}$ above the valence band maximum, are identified by temperature-dependent photoluminescence. The origin of intrinsic $p$-type behavior has been ascribed to the formation of zinc vacancy and some complex acceptor center. (C) 2006 American Institute of Physics.
\end{abstract}

[DOI: 10.1063/1.2217165]

With a wide band gap of $3.37 \mathrm{eV}$ and a large exciton binding energy of $60 \mathrm{meV}$ at room temperature, $\mathrm{ZnO}$ has become an attractive material for short-wavelength optoelectronic devices, such as light-emitting diodes and laser diodes. ${ }^{1}$ Nominally undoped $\mathrm{ZnO}$ typically exhibits $n$-type conductivity, which has been ascribed to various mechanisms including interstitial hydrogen and native defects. ${ }^{2-4}$ The realization of $p$-type $\mathrm{ZnO}$ has proven difficult due to its asymmetric doping limitations. ${ }^{5}$ Fortunately, thanks to the considerable worldwide efforts, various elements have been used as p-type dopants for $\mathrm{ZnO}$, such as $\mathrm{N},{ }^{6-8} \mathrm{P},{ }^{9} \mathrm{As},{ }^{10}$ and $\mathrm{Li}^{11}$ However, it is the inexplicit $p$-type doping mechanism as well as the stability and reproducibility problems that become the bottleneck in the development of $\mathrm{ZnO}$ devices. In addition, there are a few reports on intrinsic $p$-type behavior in intentionally undoped $\mathrm{ZnO},{ }^{12-14}$ in which the oxygen pressures were optimized. In this letter, we investigate $p$-type behavior in nominally undoped $\mathrm{ZnO}$ thin films by oxygen plasma growth. Two acceptor states are identified by temperature-dependent photoluminescence (PL).

Intentionally undoped $\mathrm{ZnO}$ thin films were grown on $a$-plane (11-20) sapphire substrates by plasma-assisted lowpressure metal-organic chemical vapor deposition (MOCVD). Diethyl zinc was used as the zinc source. Oxygen plasma, generated by a radio-frequency (rf) plasma source, was employed as the oxygen source. The growth temperature ranged from 250 to $400{ }^{\circ} \mathrm{C}$ and the chamber pressure was maintained at $5 \mathrm{~Pa}$. The average thickness of the $\mathrm{ZnO}$ thin films was around $300 \mathrm{~nm}$. Hall-effect measurements were carried out in the van der Pauw configuration (BIO-RAD HL5500PC) at room temperature. The insulating sapphire substrates assured that the measured electrical properties came from the $\mathrm{ZnO}$ thin films. Thus, necessary caution should be exercised in the previous reports on intrinsic

\footnotetext{
a) Author to whom correspondence should be addressed; electronic mail:
} yezz@zju.edu.cn $p$-type $\mathrm{ZnO}$ on silicon substrates. ${ }^{12,14}$ Moreover, $\mathrm{ZnO} p-n$ homojunction was fabricated by deposition of an intrinsic $p$-type $\mathrm{ZnO}$ layer on an $n$-type layer. The depth profile of $\mathrm{ZnO}$ thin film was investigated by a Cameca IMS-3f secondary ion mass spectroscopy (SIMS). Finally, temperaturedependent PL measurements were performed using a $\mathrm{He}-\mathrm{Cd}$ $325 \mathrm{~nm}$ laser as the excitation source.

The results of Hall-effect measurements are summarized in Table I. It shows that $p$-type conductivity with a hole concentration above $10^{17} \mathrm{~cm}^{-3}$ can be achieved at the growth temperatures of 250 and $300{ }^{\circ} \mathrm{C}$. It is speculated that the oxygen chemical potential is enhanced by virtue of oxygen plasma, which can lower the formation energy of some acceptor defect, such as zinc vacancy, ${ }^{5}$ and thus accounts for the $p$-type conductivity. Increasing the growth temperature to 350 and $400{ }^{\circ} \mathrm{C}$ results in $n$-type conductivity with an electron concentration around $10^{17} \mathrm{~cm}^{-3}$. The inversion to $n$-type conductivity can be explained as the compensation effect by the ionized oxygen vacancy donor, which is ready to form at a high growth temperature. ${ }^{15}$ Note that this electron concentration is lower than $10^{18}-10^{19} \mathrm{~cm}^{-3}$ typically grown in the same MOCVD system without a rf source, suggesting that the background electron concentration not only in $n$ type but also in $p$-type $\mathrm{ZnO}$ could be suppressed by using a rf source. However, the sample grown at a moderate temperature of

TABLE I. Electrical properties of nominally undoped $\mathrm{ZnO}$ thin films grown at different substrate temperatures.

\begin{tabular}{ccccc}
\hline \hline $\begin{array}{c}\text { Substrate } \\
\text { temperature } \\
\left({ }^{\circ} \mathrm{C}\right)\end{array}$ & $\begin{array}{c}\text { Resistivity } \\
(\Omega \mathrm{cm})\end{array}$ & $\begin{array}{c}\text { Hall } \\
\text { mobility } \\
\left(\mathrm{cm}^{2} / \mathrm{V} s\right)\end{array}$ & $\begin{array}{c}\text { Carrier } \\
\text { concentration } \\
\left(\mathrm{cm}^{-3}\right)\end{array}$ & $\begin{array}{c}\text { Carrier } \\
\text { type }\end{array}$ \\
\hline 250 & 15.8 & 1.86 & $2.12 \times 10^{17}$ & $p$ \\
300 & 12.7 & 2.6 & $1.88 \times 10^{17}$ & $p$ \\
325 & 269.8 & 2.06 & $7.27 \times 10^{15}$ & $p$ \\
350 & 18.5 & 6.63 & $5.2 \times 10^{16}$ & $n$ \\
400 & 2.24 & 7.36 & $3.75 \times 10^{17}$ & $n$ \\
\hline \hline
\end{tabular}




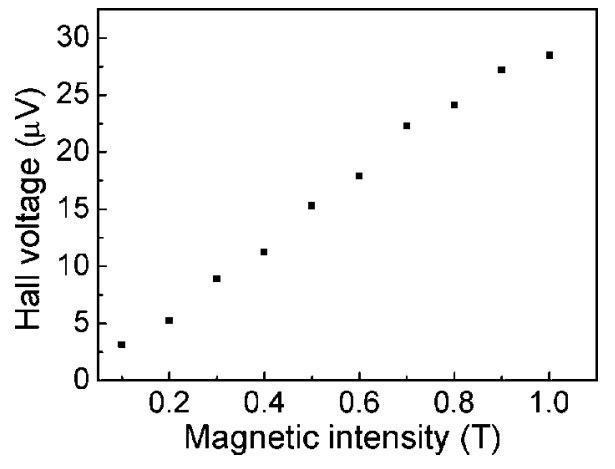

FIG. 1. The variation of Hall voltage as a function of magnetic intensity for the $p$-type $\mathrm{ZnO}$ thin film grown at $300{ }^{\circ} \mathrm{C}$.

$325^{\circ} \mathrm{C}$ gives a weak $p$-type signal with a low hole concentration of $7.27 \times 10^{15} \mathrm{~cm}^{-3}$, indicating a carrier-type transition around this temperature. Furthermore, Hall voltage was measured as a function of magnetic intensity for the sample grown at $300{ }^{\circ} \mathrm{C}$, as shown in Fig. 1. The definitive positive Hall voltages under all magnetic intensity and their quasilinear relation confirm the $p$-type conductivity in our sample.

$\mathrm{ZnO} p-n$ homojunction was prepared via a two-step process: an intrinsic $n$-type $\mathrm{ZnO}$ layer without a rf source was grown first, followed by an intrinsic $p$-type $\mathrm{ZnO}$ layer by using a rf source. In-Zn alloy was used as both $n$-side and $p$-side electrodes, showing linear $I-V$ characteristics indicative of good Ohmic behavior, as illustrated in the inset in Fig. 2. Figure 2 shows $I-V$ characteristics of the $\mathrm{ZnO}$ homojunction. The device exhibits rectification for repeated measurements, which is consistent with the formation of a $p$ - $n$ junction at the interface.

The depth profile of the $\mathrm{ZnO}$ homojunction was investigated by SIMS measurements. It can be seen from Fig. 3 that the two-layer structure is clearly identified. It is also found that the oxygen concentration increases evidently in the $p$-type layer whereas the zinc concentration shows no detectable difference in the two layers. Therefore, it is inferred that employing a rf source not only lowers the formation energy of some acceptor defects, as mentioned above, but also compensates for the oxygen vacancy donor, which are both favored towards $p$-type doping in $\mathrm{ZnO}$. In addition, no unintentionally doped acceptor element, such as nitrogen, has been detected by SIMS, which confirms the intrinsic nature of the $p$-type $\mathrm{ZnO}$.

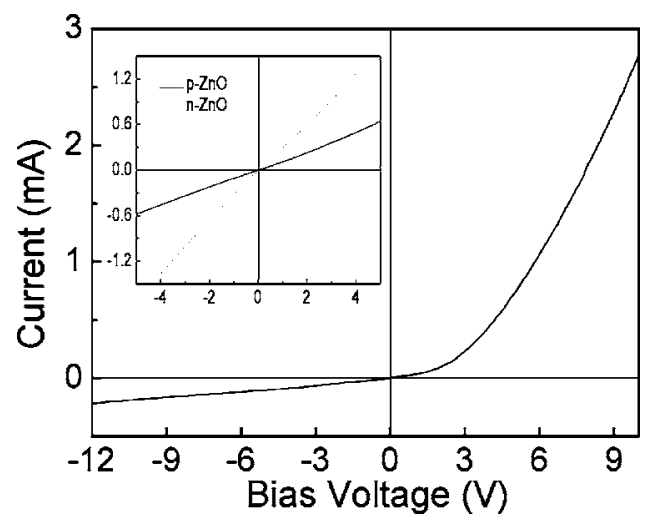

FIG. 2. $I-V$ characteristics of $\mathrm{ZnO} p-n$ homojunction measured at room temperature. The inset shows $I-V$ characteristics of $I n / Z n$ alloy contacts on the $\mathrm{ZnO}$ thin films. he $\mathrm{ZnO}$ thin films.
Downloaded 28 Jun 2006 to 61.175 .193 .51 . Redistribution subject to AlP license or

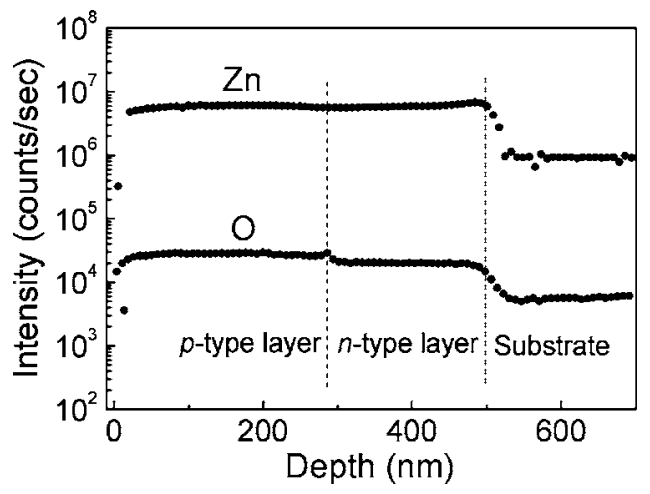

FIG. 3. SIMS depth profile of double-layer-structured $\mathrm{ZnO} p-n$ homojunction.

To better understand the intrinsic $p$-type behavior, temperature-dependent PL measurements were performed. Figure 4(a) illustrates $8 \mathrm{~K}$ PL spectrum for the $p$-type $\mathrm{ZnO}$ thin film grown at $300{ }^{\circ} \mathrm{C}$. The strong UV emission with weak visible band indicates that the $\mathrm{ZnO}$ thin film is of high optical quality. The inset shows Gaussian fitting to the nearband-edge emission peak, consisting of three bands centered at $3.33,3.27$, and $3.16 \mathrm{eV}$, labeled as $A, B$, and $C$, respectively. From these peak positions, we tentatively assign band $A$ to a neutral acceptor-bound exciton emission $\left(A^{\circ} X\right)$ and the others to two free-to-neutral-acceptor $\left(e, A^{\circ}\right)$ transitions.

To support our assignment, temperature-dependent peak positions of these three bands are plotted in Fig. 4(b). For band $A$, an obvious temperature-dependent blueshift from $3.33 \mathrm{eV}$ at $8 \mathrm{~K}$ to $3.36 \mathrm{eV}$ at $70 \mathrm{~K}$ is observed. We suggest that this PL peak gradually changes from $\left(A^{\circ} X\right)$ emission to free exciton (FX) emission with increasing temperatures due
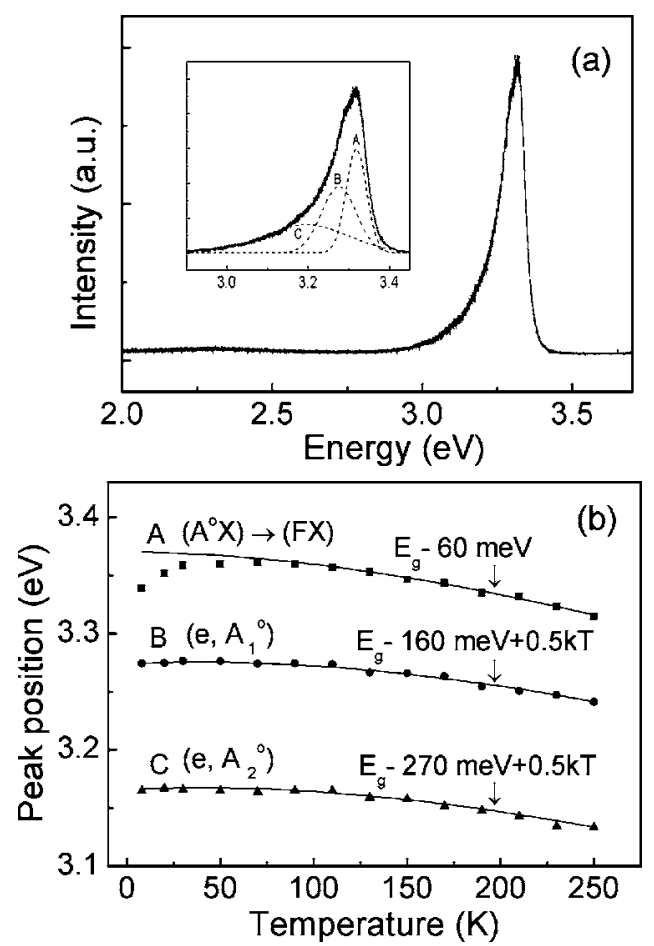

FIG. 4. (a) $8 \mathrm{~K} \mathrm{PL}$ spectrum for the $p$-type $\mathrm{ZnO}$ thin film grown at $300{ }^{\circ} \mathrm{C}$. The inset shows Gaussian fitting to the near-band-edge emission peak. (b) Temperature-dependent peak positions and their fitting curves for bands $A$, 
to the thermal effect. The temperature-dependent band gap is described according to Ref. 16 as

$$
E_{g}(T)=E_{g}(0)-\alpha T^{2} /(T+\beta),
$$

where $E_{g}(T)$ is the temperature-dependent band gap energy, $\alpha$ and $\beta$ are constants, and $T$ is the temperature. A fitting curve of $E_{g}-60 \mathrm{meV}$, as illustrated in Fig. 4(b), confirms its typical FX characteristics above $70 \mathrm{~K}$. A similar transition from bound exciton emission to FX emission has also been observed in $\mathrm{GaN}$, with the same transition temperature at $70 \mathrm{~K}^{17}$

For bands $B$ and $C$, two acceptor energy levels, located at 160 and $270 \mathrm{meV}$ above the valence band maximum, are obtained from

$$
E_{A}=E_{g}-E_{e A}+k_{B} T / 2,
$$

where $E_{e A}$ is the temperature-dependent $\left(e, A^{\circ}\right)$ transition, $E_{A}$ is the acceptor energy level, and $k_{B}$ represents Boltzmann constant. Furthermore, we fit the $\left(e, A^{\circ}\right)$ peak positions with Eq. (2), as shown in Fig. 4(b). A perfect match between the experimental values and the fitting curves supports our assignment of the $\left(e, A^{\circ}\right)$ transitions.

There are some intrinsic defects, such as zinc vacancy and oxygen antisite, behaving as acceptors in $\mathrm{ZnO}$. Zinc vacancy has lower formation energy and may serve as the dominant acceptor in intrinsic $\mathrm{ZnO} .{ }^{5,18,19}$ Moreover, there are several reports on zinc vacancy-related emission, such as $3.028 \mathrm{eV}$ at $20 \mathrm{~K},{ }^{13} 3.1 \mathrm{eV}$ at $80 \mathrm{~K},{ }^{20}$ and $3.09 \mathrm{eV}$ at $6 \mathrm{~K}^{21}$ In particular, recent calculation suggests that the $\varepsilon(2-/ 1-)$ transition level of zinc vacancy is located at $270 \mathrm{meV}$ above the valence band maximum. ${ }^{22}$ With this available literature, we tentatively attribute our $3.16 \mathrm{eV}\left(e, A^{\circ}\right)$ transition to zinc vacancy-related acceptor, with an energy level of $270 \mathrm{meV}$. It may be a simple zinc vacancy acceptor or binding to some unintentionally doped donor, such as hydrogen or aluminum. However, the origin of another $160 \mathrm{meV}$ shallow acceptor has not been clear now. This acceptor should be a complex acceptor center because it seems too shallow for a simple, intrinsic acceptor. ${ }^{23}$

In summary, we have demonstrated the reproducible growth of intrinsic $p$-type $\mathrm{ZnO}$ thin films by plasma-assisted MOCVD. The $p$-type behavior is temperature dependent. The increment of the oxygen concentration in the intrinsic $p$-type $\mathrm{ZnO}$, compared with the intrinsic $n$-type layer, is well confirmed by SIMS. The origin of intrinsic $p$-type behavior has been ascribed to the formation of zinc vacancy and some complex acceptor center. Understanding of these intrinsic acceptor states will help elucidate the extrinsic as well as intrinsic $p$-type doping mechanism in $\mathrm{ZnO}$.

This work was supported by National Natural Science Foundation of China under Contract Nos. 50532060 and 50572095 and Zhejiang Provincial Natural Science Foundation of China Under Grant No. Y405126.

${ }^{1}$ D. C. Look, Mater. Sci. Eng., B 80, 383 (2001).

${ }^{2}$ C. G. Van de Walle, Phys. Rev. Lett. 85, 1012 (2000).

${ }^{3}$ S. F. J. Cox, E. A. Davis, S. P. Cottrell, P. J. C. King, J. S. Lord, J. M. Gil, H. V. Alberto, R. C. Vilao, J. Piroto Duarte, N. Ayres de Campos, A. Weidinger, R. L. Lichti, and S. J. C. Irvine, Phys. Rev. Lett. 86, 2601 (2000).

${ }^{4}$ A. F. Kohan, G. Ceder, D. Morgan, and C. G. Van de Walle, Phys. Rev. B 61, 15019 (2000).

${ }^{5}$ S. B. Zhang, S.-H. Wei, and A. Zunger, Phys. Rev. B 63, 075205 (2001).

${ }^{6}$ D. C. Look, D. C. Reynolds, C. W. Litton, R. L. Jones, D. B. Eason, and G. Cantwell, Appl. Phys. Lett. 81, 1830 (2002).

${ }^{7}$ J. F. Rommeluere, L. Svob, F. Jomard, J. Mimila-Arroyo, A. Lusson, V. Sallet, and Y. Marfaing, Appl. Phys. Lett. 83, 287 (2003).

${ }^{8}$ W. Z. Xu, Z. Z. Ye, T. Zhou, B. H. Zhao, L. P. Zhu, and J. Y. Huang, J. Cryst. Growth 265, 133 (2004).

${ }^{9}$ K. K. Kim, H. S. Kim, D. K. Hwang, J. H. Lim, and S. J. Park, Appl. Phys. Lett. 83, 63 (2003)

${ }^{10}$ D. C. Look, G. M. Renlund, R. H. Burgener, and J. R. Sizelove, Appl. Phys. Lett. 85, 5269 (2004)

${ }^{11}$ Y. J. Zeng, Z. Z. Ye, W. Z. Xu, D. Y. Li, J. G. Lu, L. P. Zhu, and B. H. Zhao, Appl. Phys. Lett. 88, 062107 (2006).

${ }^{12}$ G. Xiong, J. Wilkinson, B. Mischuck, S. Tuzemen, K. B. Ucer, and R. T. Williams, Appl. Phys. Lett. 80, 1195 (2002).

${ }^{13}$ Y. Ma, G. T. Du, S. R. Yang, Z. T. Li, B. J. Zhao, X. T. Yang, T. P. Yang, Y. T. Zhang, and D. L. Liu, J. Appl. Phys. 95, 6268 (2004).

${ }^{14}$ M.-S. Oh, S.-H. Kim, and T.-Y. Seong, Appl. Phys. Lett. 87, 122103 (2005).

${ }^{15}$ Z. Q. Chen, S. Yamamoto, M. Maekawa, A. Kawasuso, X. L. Yuan, and T. Sekiguchi, J. Appl. Phys. 94, 4807 (2003).

${ }^{16}$ L. J. Wang and N. C. Gilesa, J. Appl. Phys. 94, 973 (2003).

${ }^{17}$ C. L. Wu, J. C. Wang, M. H. Chan, T. T. Chen, and S. Gwoa, Appl. Phys. Lett. 83, 4530 (2003).

${ }^{18}$ A. F. Kohan, G. Ceder, and D. Morgan, Phys. Rev. B 61, 15019 (2000).

${ }^{19}$ F. Tuomisto, V. Ranki, K. Saarinen, and D. C. Look, Phys. Rev. Lett. 91, 205502 (2003).

${ }^{20}$ T. V. Butkhuzi, A. V. Bureyev, A. N. Georgobiani, N. P. Kekelidze, and T. G. Khulordava, J. Cryst. Growth 117, 366 (1992).

${ }^{21}$ S. H. Jeong, B. S. Kim, and B. T. Lee, Appl. Phys. Lett. 82, 2625 (2003).

${ }^{22}$ W.-J. Lee, J. Kang, and K. J. Chang, Phys. Rev. B 73, 024117 (2006).

${ }^{23}$ J. Gutowski, N. Presser, and I. Broser, Phys. Rev. B 38, 9746 (1988). 